\title{
Redactioneel
}

\section{Over een gelukkig huwelijk tussen wetenschap en praktijk en een bruidsschat die al voorzien is in de Omgevingswet}

\author{
Prof. mr. H.F.M.W. (Marleen) van Rijswick*
}

Er is veel gebeurd sinds de Vereniging voor Bouwrecht (VBR) in 2012 haar preadviezen wijdde aan het thema: 'Naar een nieuw omgevingsrecht'. ${ }^{1}$ Op dat moment was het nog zoeken naar de wijze waarop de Omgevingswet ingevuld zou kunnen of moeten worden. De meeste discussies tijdens de ledenvergadering waren technischjuridisch van aard, hoewel er nog geen definitieve wettekst beschikbaar was, laat staan voorstellen voor de lagere regelgeving, de aanbouwwetgeving of een voorstel voor een invoeringswet. De vraag of, en zo ja hoe, de Omgevingswet eruit zou moeten zien om een effectief instrumentarium te bieden voor de grote opgaven van onze tijd - denk aan de energietransitie, aanpassing aan klimaatverandering, de circulaire economie - werd weliswaar gesteld, maar niet interessant genoeg gevonden om verdergaand te bediscussiëren. De vraag paste wellicht toen nog niet in de belevingswereld van veel juristen. Daarbij is het ook een lastige vraag.

Hoe anders was dat op de ledenvergadering van 24 november 2016 van de Vereniging voor Milieurecht (VMR) waar preadviezen over 'Milieubescherming in het omgevingsplan' werden besproken. Het was opmerkelijk dat bijna alle sprekers refereerden aan de meer overkoepelende thema's en milieuproblemen waar de

Prof. mr. H.F.M.W. van Rijswick is hoogleraar Europees en nationaal waterrecht en leidt het Utrecht Centre for Water, Oceans and Sustainability Law (UCWOSL).

1. C.W. Backes, N.S.J. Koeman, F.C.M.A. Michiels, A.G.A. Nijmeijer, H.F.M.W. van Rijswick, B.J. Schueler, J. Struiksma \& R. Uylenburg (red.), Naar een nieuw omgevingsrecht (Preadviezen voor de Vereniging voor Bouwrecht), Den Haag: Instituut voor Bouwrecht 2012.
Omgevingswet een antwoord op moet gaan bieden. ${ }^{2}$ Dat verschil in benadering ligt mijns inziens niet per se aan de verschillen tussen de verenigingen. De preadviseurs waren immers deels dezelfde personen, alhoewel de preadviezen uit 2012 door wetenschappers zijn geschreven en de preadviezen uit 2016 door een mix van wetenschappers en praktijkjuristen.

Naar mijn oordeel is er de afgelopen jaren een ommekeer in denken tot stand gekomen. Ik weet niet of dit dankzij of ondanks de Omgevingswet heeft plaatsgevonden. Eerder denk ik dat het een maatschappelijk verschijnsel is. Het is op zijn minst nieuw en bemoedigend om te zien dat het bedrijfsleven voor de verkiezingen de politiek vraagt duidelijke keuzes te maken zodat er meer zekerheid komt hoe te investeren in verdergaande duurzame ontwikkeling, de energietransitie en de circulaire economie. Klimaatverandering wordt breed gezien als een bedreiging waar maatregelen voor nodig zijn, waarbij zowel mitigatie als adaptatie van groot belang is. ${ }^{3}$ Men hoort ook steeds vaker van lokale initiatieven om de leefomgeving te verbeteren; geinitieerd door bewoners en gefaciliteerd door de overheid. De gemeente Utrecht neemt met haar milieuzones waarin vervuilende auto's worden geweerd uit het stadscentrum verdergaande maatregelen en die blijven bij de rechter in stand. Ook de fietssnelwegen in en rond Utrecht zijn een succesvol initiatief dat het makkelijker maakt de

2. N. Teesing (red.), Milieubescherming in het omgevingsplan (Publicatie van de Vereniging voor Milieurecht, 2016-1), Den Haag: Boom juridisch 2017, met bijdragen van S. Bartel, H. Borgers, E. Broeren, H. Damen, M. Dieperink, A. Freriks, K. de Graaf, J. Gundelach, K. Krijt, V. van 't Lam, T. Nijmeijer, B. Rademaker, M. Soppe, H. Tolsma en W. de Vos.

3. Alhoewel er altijd fervente non-believers blijven. 
auto te laten staan en met de fiets naar werk of school te gaan, ook als men vanuit randgemeenten als Nieuwegein of Houten komt. In een recent onderzoek naar de wijze waarop Rotterdam, Amsterdam en Utrecht hun steden klimaatbestendig proberen te maken door meer groene daken, meer groene ruimte en extra opvang voor regenwater te creëren, viel op dat deze gemeenten bij voorkeur nog kiezen voor niet-bindende beleidsinstrumenten. Het gaat dan bijvoorbeeld om voorlichting, subsidies, het faciliteren van bewonersinitiatieven enzovoort. ${ }^{4}$ Op dit moment loopt een campagne om burgers te bewegen weer voor groen in hun tuinen te kiezen en niet meer alles te betegelen. Decentrale overheden maken nauwelijks gebruik van de wettelijke bevoegdheden die men heeft, ondanks dat vergelijkend onderzoek met het buitenland laat zien dat de effectiviteit dan enorm wordt vergroot. ${ }^{5}$ Waarom het beschikbare juridisch instrumentarium niet wordt benut, is onduidelijk.

Wel is duidelijk dat veel gemeenten de huidige opgaven als een gedeelde publieke en private verantwoordelijkheid zien. Dat geldt ook voor provincies, waterschappen en de rijksoverheid. De Omgevingswet dient deze gedeelde verantwoordelijkheid op zijn minst te faciliteren. Dat kan door duidelijke normen te stellen, zodat helder is waar de zorgplicht van de overheid ophoudt en die van burgers begint. Dat moet ook plaats gaan vinden door het vroegtijdig betrekken van burgers bij nieuwe economische en ruimtelijke ontwikkelingen, bij voorkeur op het moment dat zij nog een daadwerkelijke inbreng kunnen leveren. Dat vraagt om nieuwe vormen van participatie. Een thema waar de gemiddelde jurist niet erg bekend mee is. Iets anders wat opvalt, is dat daar waar de Omgevingswet aanvankelijk sterk de nadruk legde op problemen - het oplossen van complexe en knellende regelgeving om het bedrijfsleven meer ruimte te geven - de maatschappelijke discussie nu gaat over oplossingen. Het gaat hierbij om de vraag hoe we het samen met publieke en private partijen voor elkaar krijgen om ons land toekomstbestendig te maken, met aandacht voor mens, natuur en economie. Het lijkt misschien een subtiel verschil, maar ik ben van mening dat dit een grote verandering is. De overheid lijkt achterop te lopen op maatschappelijke ontwikkelingen. Daar waar de omgevingswetgeving nog sterk leunt op het klassieke huis van Thorbecke zijn in de praktijk heel andere samenwerkingsvormen in opkomst, en die overstijgen vaak de traditionele grenzen van ministeries, provincies, gemeenten en waterschappen.

4. R. Wörner, L. Dai \& H. van Rijswick, Rainproof cities in the Netherlands. A comparative study of Dutch governance approaches to climate adaptive urban planning, under review.

5. H. Mees, Local governments in the driving seat? A comparative analysis of public and private responsibilities for adaptation to climate change in European and North-American cities, Journal of Environmental Policy and Planning 2016, p. 1-17; H. Mees, Responsible climate change adaptation - Exploring, analysing and evaluating public and private responsibilities for urban adaptation to climate change (diss. Utrecht), 2014; H.L.P. Mees, P.P.J. Driessen, H.A.C. Runhaar \& J. Stamatelos, Who governs climate adaptation? Getting green roofs for stormwater retention off the ground, Journal of Environmental Planning and Management (56) 2013, afl. 6, p. 802-825.
Om de transitie naar een meer duurzame samenleving te bewerkstelligen, zijn er meer soorten gedeelde verantwoordelijkheden nodig.

Zo zullen oplossingen tot stand komen door middel van technologische innovaties, financiële mogelijkheden, juridische inpassing en meer bestuurskundige ondersteuning van beleidsprocessen. Dat alles zal moeten passen bij waarden en beginselen die we als samenleving belangrijk vinden. Dat vraagt om een samenwerking over disciplines heen en zal voor sommige juristen nieuw zijn. Het is juist de praktijk die deze aanpak al gewend is: in bedrijven zal men zich altijd moeten verdiepen in de vraag wat collega's doen, en ook bij overheden is men gewend met collega's van andere disciplines te werken. De samenwerking tussen verschillende disciplines zal cruciaal zijn om een antwoord te bieden op de duurzaamheidsvragen die dit moment spelen.

Dat neemt echter niet weg dat ook het recht zijn eigen vragen heeft als het gaat om de transitie naar een duurzame samenleving. Dat vraagt onder meer om een grondige bestudering van de Omgevingswet en de bijbehorende lagere regelgeving, maar ook van regelgeving op aanpalende beleidsterreinen als energie, landbouw, mijnbouw, visserij enzovoort. En dat geldt ook niet alleen als die regelgeving tot stand wordt gebracht, maar ook bij de verdere implementatie, toepassing en handhaving de komende jaren. De vraag rijst hoe we die kennis gaan ontwikkelen.

Tegelijkertijd met de invoering van de Omgevingswet is een traject opgestart om eenieder die met de Omgevingswet te maken krijgt voor te lichten en op te leiden. Dat gebeurt deels vanuit het ministerie van Infrastructuur en Milieu, deels door commerciële opleidingscentra en deels vanuit hogescholen, universiteiten en beroepsverenigingen, zoals de hiervoor al genoemde Vereniging voor Bouwrecht en de Vereniging voor Milieurecht. Iedere 'opleider' heeft zijn eigen doelgroep en dat is ook goed.

Voorlichten en opleiden is echter niet hetzelfde als de grondige bestudering van het omgevingsrecht. Dat vindt idealiter óók plaats op de universiteiten. En daar gaat in mijn ogen iets mis. Het geldt wellicht niet voor alle universiteiten, maar over het algemeen is het zo dat de afgelopen jaren veel van het vrij te besteden onderzoeksgeld van de universiteiten is overgeheveld naar NWO, de nationale onderzoeksorganisatie, die vervolgens het onderzoeksgeld weer verdeelt over de universiteiten. Dat is op zichzelf geen probleem, maar de competitie is enorm en de 'calls' waar men op mee kan dingen om geld voor onderzoek te krijgen, zijn vaak vrij gedetailleerd omschreven en men moet aan allerlei vereisten voldoen, zoals zorg dragen voor interdisciplinaire en vaak internationale consortia, het regelen van cofinanciering door private en publieke partijen, aangeven wat het wetenschappelijke en maatschappelijke belang is van het onderzoek en soms ook hoe het Nederlandse bedrijfsleven kan verdienen aan het onderzoek. Datzelfde geldt voor financiering vanuit de topsectoren en de EU-onderzoeksbudgetten, alsmede andere onderzoeks- 
budgetten. De administratieve lasten die daarmee gepaard gaan, zijn enorm en het slagingspercentage ligt momenteel tussen de 6 en 10\%. Dat betekent dat onderzoekers een groot deel van hun onderzoekstijd kwijt zijn met het schrijven van onderzoeksvoorstellen, het vormen van consortia en het vinden van cofinanciering, waar vervolgens niets uit voortvloeit. In mijn ogen is dat een verspilling van tijd en capaciteit. Daarbij leiden dit soort onderzoeken vaak tot Engelstalige publicaties in tijdschriften die in ieder geval de Nederlandse praktijkjuristen nauwelijks lezen of zelfs niet eens kennen. $\mathrm{Nu}$ hebben juristen zich in het verleden weinig aangetrokken van deze onderzoeksfinanciering, ook omdat de kans op succes voor juristen nog kleiner was dan voor andere disciplines.

Ik constateer echter dat er binnen de wetenschap steeds minder ruimte en budget beschikbaar is voor puur juridisch onderzoek. Ook de systematische evaluaties, zoals van de vroegere ECWM en de STEM-onderzoeken, vinden niet meer plaats. Tegelijkertijd ben ik van mening dat de invoering, implementatie en daadwerkelijke toepassing van de Omgevingswet gebaat kan zijn met een actieve en constante inbreng vanuit de wetenschap. Ik meen dan ook dat het zaak is hiervoor financiering te vinden. Die financiering is immers ook voor ander wetenschappelijk onderzoek beschikbaar. Het heeft mij verbaasd dat er vanuit het ministerie geen aandacht is geweest voor dit gebrek aan financiering voor wetenschappelijk juridisch onderzoek bij de ontwikkeling van de Omgevingswet, terwijl er wel onderzoeksbudgetten beschikbaar zijn bij het ministerie. Ook de juridische adviescommissies zijn opgeheven, zodat ook op die wijze geen inbreng aan de discussie meer wordt geleverd. Het ministerie en de decentrale overheden kunnen wel een belangrijke rol spelen bij de vormgeving van de zogenaamde calls bij NWO en het Topsectorenbeleid, maar hebben dit tot dusver niet gedaan waar het gaat om de verdere bestudering en ontwikkeling van het omgevingsrecht. Maar het is nog niet te laat om dit alsnog te doen!

Op dit moment wordt er veel werk verricht door adviesbureaus, door middel van detacheringen en door middel van ad-hocadviesopdrachten aan universiteiten op kleinere deelonderwerpen. Dat is ook goed en kan zo blijven. Dat is echter iets anders dan onafhankelijk wetenschappelijk onderzoek, dat niet afhankelijk is van politieke wensen en deadlines. Voor onderlinge concurrentie hoeven we niet erg bevreesd te zijn. De deskundigheid (in aantallen personen) op het terrein van het omgevingsrecht is beperkt op de Nederlandse universiteiten en wordt steeds minder. En dat terwijl er veel werk te verrichten is. De vragen die ik hiervoor al noemde - Wat kunnen het omgevingsrecht en de Omgevingswet bijdragen aan de transitie naar een duurzame samenleving? Hoe geven we de energietransitie juridisch vorm? Hoe passen we ons aan aan klimaatverandering? Hoe gaan we de circulaire economie juridisch vormgeven? Wat kunnen we doen aan de steeds verdergaande bodemdaling, waar niemand verantwoordelijkheid voor neemt? Hoe geven we invulling aan gedeelde verantwoordelijkheden tussen publieke en private partijen in dit transitieproces? - zijn nog lang niet beantwoord. Ook op de ledenvergadering van de VMR in november 2016 werden de vragen slechts gesteld en niet beantwoord. Ondanks de vergaande integratie in de Omgevingswet hebben we nog steeds te maken met gefragmenteerde wetgeving: denk aan de verticale relaties tussen omgeving-landbouw, omgeving-energie, omgevingvoedsel, omgeving-gezondheid enzovoort. Diezelfde fragmentatie ziet men terug in de institutionele vormgeving, maar dan horizontaal: internationale, Europese, nationale en decentrale regelgeving zijn niet altijd even goed op elkaar afgestemd.

Ik stel me een onderzoeksprogramma voor waar systematisch aan deze juridische vragen wordt gewerkt, in nauwe samenwerking met overheden en private partijen. Het initiatief voor zo'n programma, dat wordt ondergebracht bij NWO, kan het beste worden genomen door het ministerie van Infrastructuur en Milieu als ministerie met een eindverantwoordelijkheid voor het omgevingsbeleid. Samenwerking tussen de universiteiten zou de enige goede optie zijn in mijn ogen. Dat gebeurt nu ook al veel en goed. Elke universiteit heeft goede onderzoekers, veelal met eigen expertise. Concurrentie in zo'n klein wereldje voegt weinig toe. Ik stel me zo voor dat het een grote toegevoegde waarde zou hebben als er de komende zes jaar (de gemiddelde looptijd van een onderzoeksprogramma) vanuit de verschillende universiteiten waar men zich bezighoudt met het omgevingsrecht permanent tijd en onderzoekers beschikbaar zijn die zich kunnen verdiepen in het vernieuwde omgevingsrecht en de vragen en opgaven die nu spelen. Een fulltime onderzoeker (eventueel verdeeld over meerdere personen omdat men ook onderwijs moet geven) per universiteit en een coördinerende universiteit die zorg draagt voor de coördinatie van de onderzoeksresultaten en het organiseren van bijeenkomsten zouden dan al heel veel meer capaciteit betekenen dan nu beschikbaar is.

Dit voorstel voor een onderzoeksprogramma speciaal voor de verdere ontwikkeling van het omgevingsrecht heeft een aantal voordelen. Zo is het belangrijk om te weten dat het over het algemeen zo werkt dat als men als overheden (eventueel samen met het bedrijfsleven) 10\% investeert - de zogenaamde cofinanciering -, NWO de resterende financiering verzorgt vanuit het wetenschapsbudget. Het grote voordeel is dat men onderzoek kan doen dat direct relevant is voor de Nederlandse praktijk, dat geschreven kan worden in het Nederlands (wat voor het Nederlandse recht en de Nederlandse praktijk toch vaak praktisch is), waarbij men zowel meer fundamentele en langer lopende vragen kan onderzoeken als praktische vragen die zich in de loop van het implementatieproces voordoen, en dat men een forum creëert waar de Nederlandse juridisch-wetenschappelijke onderzoekers continu met elkaar en de praktijk in discussie kunnen gaan en blijven, zonder afhankelijk te zijn van ad-hocinitiatieven en de huidige gejaagde zoek- 
tocht naar financiering van onderzoek dat niet altijd even relevant is voor de praktijk.

Vanzelfsprekend kan men dit voorstel uitbreiden door onderzoekers van andere disciplines te betrekken, maar mijn zorg is juist dat er te weinig ruimte is voor juridisch onderzoek. Dat zou in zo'n opzet zeker gewaarborgd moeten zijn. Dat neemt niet weg dat de aldus ontwikkelde kennis door juristen kan worden ingebracht in multidisciplinaire consortia en onderzoeksprogramma's. Maar om dat goed te kunnen doen moet men ook deskundig zijn op het eigen vakgebied. En dat vraagt constante en structurele investeringen in onderzoek, juist in deze tijd waar het gehele omgevingsrecht wordt veranderd. Datzelfde geldt overigens voor het onderwijs. We hebben voor de toekomst veel goed opgeleide omgevingsrechtjuristen nodig die een maatschappelijke bijdrage kunnen leveren aan de transitie naar een duurzame samenleving.

Deze bijdrage kan dan ook worden gezien als een warm pleidooi, eigenlijk echt een hartenkreet, voor een initiatief om onderzoeksgelden vrij te maken voor het omgevingsrecht en de Omgevingswet in het bijzonder. Op die wijze kan worden gewerkt aan een gelukkig huwelijk tussen wetenschap en praktijk.

Ondanks mijn zorgen staat dit nummer van het Tijdschrift voor Omgevingsrecht weer boordevol nuttige informatie, waar ook het nodige onderzoek aan ten grondslag ligt.

Ook in deze aflevering vindt $\mathrm{u}$ een actuele stand van de stelselherziening, verzorgd door Wilco de Vos. Aandacht wordt besteed aan de consultatie en de parlementaire behandeling van de vier ontwerp-AMvB's op grond van de Omgevingswet: het Besluit kwaliteit leefomgeving (Bkl), het Besluit activiteiten leefomgeving (Bal), het Besluit bouwwerken leefomgeving (Bbl) en het Omgevingsbesluit (Ob). Daarnaast wordt ingegaan op de zogenaamde 'eerste module' van de Omgevingswet. Dit betreft de Omgevingswet zoals die is gepubliceerd in het Staatsblad, aangevuld met de aanvullingswetten bodem, geluid, grondeigendom, natuur en de invoeringswet.

Over de Aanvullingswet bodem is recent onderzoek gedaan door Annelies Freriks en Petra Lindhout, naar aanleiding van de zorgen die de drinkwaterbedrijven hebben over het vervallen van een beschermingsregime en instrumentarium voor historische verontreinigingen. ${ }^{6}$ Een artikel zal daar binnenkort over verschijnen. Over de Aanvullingswet natuur gaat de bijdrage 'Gebiedsbescherming en soortenbescherming in de Aanvullingswet natuur Omgevingswet' van Chris Backes en Annelies Freriks in dit nummer. De Invoeringswet Omgevingswet zal ook gevolgen hebben voor de nadeelcompensatieregeling. De titel van de bijdrage van Berthy van den Broek en Michiel Tjepkema 'De nadeelcompensatieregeling in de Omgevingswet: geen aantrekkelijk alternatief voor het huidige planschadestelsel' doet al ver- moeden dat auteurs kritische kanttekeningen plaatsen bij de voorgestelde nieuwe regeling.

Ik wens u veel leesplezier. 